\section{Regards sur l'économie allemande}

Bulletin économique du CIRAC

$70 \mid 2005$

Varia

\title{
La persévérance réformatrice commence à porter ses fruits
}

René Lasserre

\section{OpenEdition}

Édition électronique

URL : http://journals.openedition.org/rea/1843

DOI : 10.4000/rea.1843

ISBN : 978-2-8218-0836-2

ISSN : 1965-0787

\section{Éditeur}

CIRAC

Édition imprimée

Date de publication : 1 mars 2005

Pagination : 1-2

ISSN : 1156-8992

\section{Référence électronique}

René Lasserre, "La persévérance réformatrice commence à porter ses fruits », Regards sur l'économie allemande [En ligne], 70 | mars 2005, mis en ligne le 16 décembre 2008, consulté le 22 septembre 2020. URL : http://journals.openedition.org/rea/1843 ; DOI : https://doi.org/10.4000/rea.1843 


\section{La persévérance réformatrice commence à porter ses fruits}

Le ralentissement conjoncturel du dernier trimestre 2004 a singulièrement refroidi le climat d'optimisme qui avait salué la reprise au printemps, tandis que le gonflement 'statistique' des chiffres du chômage en début d'année est venu semer le doute sur la capacité de l'économie allemande à sortir de l'ornière. Pourtant, les incertitudes liées au renchérissement du pétrole et à l'euro fort ne parviennent pas à éclipser les signes tangibles d'un redressement durable. Le nouveau record historique enregistré à l'exportation témoigne d'une compétitivité industrielle allemande vigoureuse qui commence à engranger les dividendes d'une globalisation pleinement assumée.

L'étude que nous publions sur l'engagement de l'industrie allemande en Chine, en Inde et au Brésil met clairement en évidence une stratégie offensive, bien que sélective, d'investissement direct dans les pays émergents qui conforte les positions acquises sur le marché européen et la percée réalisée en Europe centrale. L'industrie allemande tire pleinement parti de son insertion croissante dans le marché mondial. Sur la base de fortes spécialisations sectorielles et d'implantations géographiques diversifiées, les entreprises allemandes cultivent leurs avantages compétitifs en optimisant leurs circuits de production et en renforçant leur capacité d'innovation. Forts de leur expérience et de leur savoir-faire, les grands groupes industriels sont à la pointe de ce processus, comme en témoigne la stratégie de compétitivité globale du groupe Siemens dont nous rendons compte dans le présent numéro. Mais le Mittelstand est loin d'être en reste et participe pleinement de cette dynamique compétitive qui génère de la valeur ajoutée et de nouvelles activités de services sur le marché domestique.

$\mathrm{Au}$ travers de la grisaille persistante du marché intérieur, on discerne également de multiples signes annonciateurs d'embellie. La bonne tenue de la dépense publique n'est certes pas de nature à débrider une demande interne tout juste frémissante, mais elle témoigne au moins d'une volonté ferme de résorber les déficits, condition essentielle pour la poursuite des baisses d'impôts. Plus significatives encore sont les avancées réalisées sur le terrain difficile du marché du travail. Les réformes Hartz, fondées initialement sur le développement de formes d'emploi atypique, commencent à porter leurs fruits à travers la constitution progressive d'un segment d'emplois à coût social allégé, prélude à la flexibilité accrue du marché du travail que viendra renforcer la refonte du régime d'indemnisation.

Sur un tout autre terrain, qui n'en est pas moins décisif, celui de la recherche et de l'innovation, on constate également que le paysage allemand est loin de rester immobile. L'analyse que nous présentons du 
grand centre de recherche de Jülich et du processus de réforme dans lequel il est engagé montre combien, dans un contexte financier fortement contraint, les pouvoirs publics et les milieux scientifiques sont soucieux de promouvoir des procédures de gestion rigoureuses, fondées à la fois sur l'évaluation et la performance et sur une synergie active entre les acteurs, notamment entre les grands établissements de recherche et l'université. Le contraste est flagrant avec les blocages institutionnels et corporatistes qui paralysent désespérément le débat sur la réforme du système français d'enseignement supérieur et de recherche. Le décrochage français risque d'ailleurs de s'accentuer encore, maintenant que le Tribunal fédéral de Karlsruhe vient de lever le tabou sur les droits d'inscription à l'université, seule voie réaliste et raisonnable pour remédier au sous-financement chronique de l'enseignement supérieur.

Reste l'enjeu crucial des retraites et de leur financement : le bilan que dresse Mechthild Veil de la politique allemande de réforme du système de retraites montre qu'en dépit d'une forte volonté d'explorer des voies nouvelles, telles que la capitalisation ou les retraites d'entreprise, l'approche allemande n'est pas encore parvenue à assurer la consolidation durable de la protection vieillesse. Ce constat ne laisse d'inquiéter au regard du défi considérable que constitue le vieillissement démographique dont l'analyse prospective de Stefanie Wahl explore les implications pour le dynamisme et la compétitivité des économies européennes. L'enjeu de la protection, pour important qu'il soit, ne constitue en effet qu'un aspect du problème qui appellera des arbitrages difficiles en termes de consommation et d'investissement et des adaptations en profondeur des conditions d'emploi et des structures de production. La prise de conscience de l'ampleur des mutations sera longue. Raison de plus pour ne pas faiblir et maintenir le cap sur les réformes : l'exemple allemand montre que la persévérance réformatrice commence à porter ses fruits. 